\title{
PERENCANAAN PONDASI TIANG PANCANG GEDUNG KETAHANAN PANGAN NGANJUK
}

\author{
Bagus Anggoro Wiratmoko ${ }^{1}$, Sigit Winarto ${ }^{2}$, Yosef Cahyo SP ${ }^{3}$. \\ ${ }^{1,2,3}$ Fakultas Teknik, Universitas Kadiri. \\ e-mail:1bagus.ang@gmail.com, ${ }^{2}$ sigit.winarto@unik-kediri.ac.id, \\ 3yosef.cs@unik-kediri.ac.id.
}

\begin{abstract}
This study uses library research methods. Sources used in planning in the form of primary data and secondary data. Where the data includes soil data, pile data, and load data. The theoretical basis used is a static theoretical basis, according to Luciano Decourt, based on SPT data using manual method calculations. From the results of the calculation, it can be concluded that the results of loading on the 1st floor to the 4th floor are 6218.6 tons. Dimension and suitable pile foundation depth are Typel foundation: $3.6 \mathrm{~m}$ long, $3.6 \mathrm{~m}$ wide, $0.8 \mathrm{~m}$ high, and $1 \mathrm{~m}$ deep. Type 2 foundation: $3.6 \mathrm{~m}$ long, $5.4 \mathrm{~m}$ wide, $0.8 \mathrm{~m}$ high, and $1 \mathrm{~m}$ deep. The importance of foundation reinforcement is $70089.8 \mathrm{~kg}$. Stability of control: - Against rolling $=24,620 \mathrm{t} / \mathrm{m} 2>1.5 \mathrm{t} / \mathrm{m} 2->$ Safe - Against shear $=9,156 \mathrm{t} / \mathrm{m} 2>1.5 \mathrm{t} / \mathrm{m} 2->$ Safe
\end{abstract}

Keywords : Foundation, Pile, Reinforced Concrete, Soil

\begin{abstract}
Abstrak
Penelitian ini menggunakan metode penelitian pustaka. sumber yang digunakan dalam perencanaan berupa data primer dan data sekunder. Dimana data tersebut meliputi data tanah, data tiang pancang, dan data beban. Landasan teori yang digunakan adalah landasan teori statis menurut Luciano Decourt berdasarkan data SPT dengan menggunakan metode perhitungan manual. Dari hasil perhitungan dapat disimpulkan bahwa hasil pembebanan pada lantai 1 sampai lantai 4 sebesar 6.218,6 ton. Dimesnsi dan kedalaman pondasi tiang yang sesuai adalah: Pondasi tipe1: panjang 3,6 m, lebar 3,6 m, tinggi 0,8 m, dan dalam $1 \mathrm{~m}$. Pondasi tipe 2: panjang 3,6 m, lebar 5,4 m, tinggi $0,8 \mathrm{~m}$, dan dalam $1 \mathrm{~m}$. Pentingnya perkuatan pondasi adalah 70089,8 kg. Kestabilan pengendalian: - Melawan rolling = 24.620 t $/ \mathrm{m} 2>1,5 \mathrm{t} / \mathrm{m} 2$-> Aman Terhadap geser $=9,156 \mathrm{t} / \mathrm{m} 2>1,5 \mathrm{t} / \mathrm{m} 2 \rightarrow$ Aman
\end{abstract}

Kata Kunci : Pondasi, Tiang Pancang, Beton Bertulang, Tanah 


\section{PENDAHULUAN}

Secara umum permasalahan pondasi dalam lebih rumit jika dibandingkan dengan pondasi dangkal. Dalam hal ini penulis lebih berkonsentrasi pada pembuatan Tugas Akhir untuk perencanaan pondasi dalam jenis tiang pancang. Pondasi tiang pancang adalah batang yang relative Panjang serta langsung yang berfungsi sebagai penyalur beban pondasi melewati lapisan tanah dengan daya dukung rendah kelapisan tanah yang mempunyai kapasitas daya dukung tinggi yang relative cukup dalam di banding pondasi dangkal, [1][2]. Daya dukung tiang pancang diperoleh dari daya dukung ujung (end bearing capacity) yang diperoleh dari tekanan ujung tiang dan daya dukung geser atau selimut (fiction bearing capacity) yang diperoleh dari daya dukung gesek atau gaya adhesi antara tiang pancang dan tanah di sekelilingnya, [3].

Salah satu factor yang mempengarui daya dukung pondasi dalam menyalurkan beban yang diterimah dari struktur atas kelapisan tanah dipengaruhi oleh daya dukung tanah. Untuk mengetahui daya dukung tanah dapat diperoleh melalui penyelidikan standar penetrasi test (SPT) dan penyelidikan sondir.

\section{METODE PENELITIAN}

\subsection{Tinjauan Umum}

Pondasi merupakan sebuah struktur bangunan yang umumnya terdiri dari satu atau lebih elemen - elemen pondasi. Dimana elemen pondasi merupakan elemen transisi / perpindahan antara tanah atau batuan dengan struktur atas. Dalam proses pembuatan desain suatu pondasi meliputi proses pemilihan jenis pondasi, proses penentuan perletakanya, proses penentuan ukuran / dimensi pondasi, hingga bagaimna proses pelaksanaan fisik kontruksinya.

\subsection{Tanah Untuk Perletakan Pondasi}

Tanah sebagai pendukung pondasi memiliki pengertian bahwa tanah tersebut digunakan untuk perletakan struktur pondasi dari suatu bangunan dan juga sebagai peyangga beban kontruksi diatasnya [4]. Jenis- jenis tanah antara lain sebagai berikut : Tanah lempung (clay), Tanah lumpur (sill), Tanah pasir (sand), Tanah berkerikil (gravel).

Tabel 1. Konsistensi Tanah menurut Luciano Decourt

\begin{tabular}{|c|c|c|c|}
\hline Konsistensi Tanah & $\mathbf{C u}$ (Kg/cm2) & SPT, N & Sondir, qn (Kg/cm2) \\
\hline Sangat lunak (very soft) & $<0.125$ & $<2.5$ & $<7.5$ \\
\hline Lunak (soft) & $0.125-0.25$ & $2.5-5$ & $7.5-15$ \\
\hline Sedang (medium stiff) & $0.25-0.5$ & $5-10$ & $15-30$ \\
\hline Kaku (Stiff) & $0.5-1.0$ & $10-20$ & $30-60$ \\
\hline Sangat kaku (very stiff) & $1.0-2.0$ & $20-40$ & $60-120$ \\
\hline Keras (Hard) & $>2.0$ & $>40$ & $>120$ \\
\hline
\end{tabular}

Sumber : Internet 
Tabel 2. Nilai koefisien berdasarkan jenis tanah metode L. Decourt (1982)

\begin{tabular}{|c|c|}
\hline Jenis Tanah & $\mathrm{K}\left(\mathrm{t} / \mathrm{m}^{2}\right)$ \\
\hline Lempung & 12 \\
\hline Lanau Berlempung & 20 \\
\hline Lanau Berpasir & 25 \\
\hline Pasir & 40 \\
\hline
\end{tabular}

Sumber : Ismail 1988, [5].

\subsection{Uji Penetrasi Standar (SPT)}

Tujuan dari percobaan SPT ini adalah untuk menentukan kepadatan relatif lapisan tanah dari pengambilan contoh tanah dengan tabung sehingga diketahui jenis tanah dan ketebalan tiaptiap lapisan kedalaman tanah dan untuk memperoleh data yang kualitatif pada perlawanan penetrasi tanah serta menetapkan kepadatan dari tanah yang tidak berkohesi yang biasa sulit diambil sampelnya, [3].

\subsection{Macam-Macam Pondasi}

Secara umum pondasi terdiri dari 2 macam, sebagai berikut :

1. Pondasi Dangkal : Pondasi Telapak, Pondasi Memanjang, Pondasi Rakit.

2. pondasi Dalam : Pondasi sumuran, Pondasi tiang pancang, Pondasi bore pile.

\subsection{Pondasi Tiang Pancang}

Pondasi tiang pancang biasanya dibuat di pabrik ( pabrikasi), (precast) dan kemudian dikirim ke lokasi proyek untuk menjalani proses pemancangan. Kapasitas tiang pancang dapat diperkirakan berdasarkan rumus-rumus empiris yang ada dengan memanfaatkan data-data sifat mekanik tanah yang diperoleh dari data sondir, [6][7].

Kelebihan dari tiang pancang sendiri adalah sebagai berikut :

- Karena pembuatanya secara pabrikasi, maka mutu beton terkontrol.

- Daya dukung tiang terbagi merata di sekeliling tiang.

- Pada tiang kelompok beban 1 tiang ditanggung tiang lainya dan memiliki daya dukung yang sangat kuat.

- Memiliki harga yang lebih murah dibandingkan pondasi sumuran.

Sedangkan kekurangan dari pondasi tiang pancang adalah :

- Terkendala akses jalan apabila akses jalan menuju lokasi proyek sempit.

- $\quad$ Tergolong system pondasi yang baru

- Proses pemancangan mengakibatkan polusi pendengaran dan getaran. Pondasi tiang pancang menurut pemakaian bahan dan karakteristik strukturnya dapat dibagi kedalam beberapa kategori, [3].

\subsection{Langkah Desain Pondasi}


Langkah - langah penentuan struktur pondasi sebagai berikut :

1. Penentuan Beban Rencana

Beban rencana merupakan beban yang diterimah oleh pondasi yaitu berupa beban dari struktur atas. Beban - beban pada struktur bangunan berupa beban hidup (beban fungsi dari struktur) dan beban mati (beban sendiri dari struktur).

2. Penyelidikan Tanah

Hal ini dilakukan untuk mendapatkan informasi mengenai daya dukung tanah dan kedalaman tanah keras. Informasi mengenai daya dukung tanah digunakan untuk menghitung besar kapasitas pondasi yang akan dipilih sedangkan kedalaman tanah keras digunakan untuk menentukan jenis pondasi yang akan digunakan [8].

3. Pemilihan Jenis Pondasi

Penentuan tipe pondasi berdasarkan pada informasi penyelidikan tanah yang telah diperoleh. Kemudian dipilih jenis pondasi yang sesuai.

4. Penentuan Dimensi Pondasi

Penentuan dimensi pondasi harus berdasarkan hasil penyelidikan tanah dana data - data lainya. Untuk menentukan dimensi pondasi tiang pancang, maka hal yang diperhitungkan adalah mengenai berapa jumlah tiang dalam pile cap serta dimensi berapa Panjang, lebar, dan tebal pile cap, [9].

5. Tahap Kontruksi

Tahap konstruksi adalah tahapan pelaksanaan perencanaan yang telah direncanakan sebelumnya [10].

\subsection{Pengertian Pembebanan}

Beban adalah gaya luar yag membebani struktur, [11]. Dalam perencanaan pondasi sangat penting menghitung beban total bangunan meliputi beban hidup dan beban mati.

a. Beban Mati

Beban mati merupakan sebuah beban yang diakibatkan oleh elemen - elemen struktur bangunan seperti kolom, balok, pelat, dinding, [12].

Tabel 3. Berat Sendiri Bahan Bangunan dari Gedung

\begin{tabular}{|c|c|c|}
\hline No. & Beban Mati & Besar Beban \\
\hline 1 & Baja & $7850 \mathrm{~kg} / \mathrm{m} 3$ \\
\hline 2 & Beton Bertulang & $2400 \mathrm{~kg} / \mathrm{m} 3$ \\
\hline 3 & Dinding pasangan $1 / 2$ batu & $250 \mathrm{~kg} / \mathrm{m} 2$ \\
\hline 4 & Dinding pasangan 1 batu & $450 \mathrm{~kg} / \mathrm{m} 2$ \\
\hline 5 & Pasangan batu bata & $1,70 \mathrm{ton} / \mathrm{m} 3$ \\
\hline 6 & pasangan batu kali & $2,00-2,20 \mathrm{ton} / \mathrm{m} 3$ \\
\hline 7 & beban tanah & $1,60-2,00 \mathrm{ton} / \mathrm{m} 3$ \\
\hline 8 & Atap genting, usuk, dan reng & $50 \mathrm{~kg} / \mathrm{m} 2$ \\
\hline
\end{tabular}

Sumber : Peraturan Pembebanan Indonesia untuk Gedung, [13]. 
b. Beban Hidup

Beban hidup merupakan sebuah beban yang tidak membebani struktur Gedung secara permanen melainkan beban yang diakibatkan oleh pengguna.

Tabel 4. Beban Hidup pada Atap Gedung

\begin{tabular}{|c|c|}
\hline Kegunaan Bangunan & Berat \\
\hline Atap gedung & $100 \mathrm{~kg} / \mathrm{m}^{2}$ \\
\hline
\end{tabular}

Sumber : Peraturan Pembebanan Indonesia untuk Gedung, [13].

Tabel 5. Beban Hidup Lantai Gedung

\begin{tabular}{|c|l|c|}
\hline No. & \multicolumn{1}{|c|}{ Beban Hidup pada lantai bangunan } & Besar Beban \\
\hline a & $\begin{array}{l}\text { Lantai dan tangga rumah tinggal, kecuali yang disebut } \\
\text { dalam b. }\end{array}$ & $200 \mathrm{~kg} / \mathrm{m} 2$ \\
\hline b & $\begin{array}{l}\text { Lantai dan tangga rumah sederhana dan gudang - gudang } \\
\text { tidak penting yang bukan untuk toko, pabrik atau bengkel. }\end{array}$ & $125 \mathrm{~kg} / \mathrm{m} 2$ \\
\hline c & $\begin{array}{l}\text { Lantai sekolah, ruang kuliah, kantor, toko, toserba, } \\
\text { restoran, hotel, asrama dan rumah sakit. }\end{array}$ & $250 \mathrm{~kg} / \mathrm{m} 2$ \\
\hline d & Lantai ruang olah raga & $400 \mathrm{~kg} / \mathrm{m} 2$ \\
\hline
\end{tabular}

Sumber : Peraturan Pembebanan Indonesia untuk Gedung, [13].

c. Beban Terfaktor

Pondasi, komponen, dan struktur dari suatu bangunan harus dirancang dengan penuh perhitungan sehingga memiliki kekuatan yang sama atau lebih dari beban terfaktor dalam kombinasi berikut:

$1,2 \mathrm{D}+1,6 \mathrm{~L}$

Keterangan :

$\mathrm{D}=\quad=$ Beban Mati

L $\quad=$ Beban Hidup, [14].

d. Beban Gempa

Beban Gempa merupakan seluruh beban statik ekivalen yang bekerja pada suatu gedung yang mencerminkan pengaruh gerakan tanah akibat gempa. Beban gempa diperoleh dari perhitungan gaya geser dasar nominal $\mathrm{V}$ dari rumus:

$\mathrm{V}=\mathrm{C} \times \mathrm{I} \times \mathrm{W} / \mathrm{R}$

Dimana:

$\mathrm{V} \quad$ = gaya geser dasar nominal

$\mathrm{C}=$ faktor respon gempa

I = faktor keutamaan gedung

$\mathrm{W}=$ = berat total gedung termasuk beban hiup yang bekerja

$\mathrm{R}=$ = faktor reduksi gempa

e. Beban Angin

Beban Angin adalah semua beban yang bekerja pada sebuah gedung atau bagian gedung 
yang disebabkan oleh perbedaan selisih dalam tekanan udara $(\mathrm{kg} / \mathrm{m} 2)$.

Besarnya muatan yang diperhitungkan adalah sebagai berikut:

1. Di daerah pedalaman (jauh dari pantai) tekanan angin diambil minimum yaitu $25 \mathrm{~kg} / \mathrm{m} 2$.

2. Tekanan angin di laut dan ditepi lautatau sejauh $5 \mathrm{~km}$ dari pantai harus diambil minimum yaitu $40 \mathrm{~kg} / \mathrm{m} 2$.

3. Untuk daerah di dekat laut dan daerah yang dimungkinkan menghasilkan tekanan tiup lebih besar tekanan tiup (p) diambil dengan persamaan :

$p=\frac{V^{2}}{16}\left(\mathrm{~kg} / \mathrm{m}^{2}\right)$

Dengan :

$\mathrm{p}$ : tekanan tiup angin dalam $\mathrm{kg} / \mathrm{m}^{2}$

$\mathrm{v}:$ kecepatan angin dalam $\mathrm{m} / \mathrm{dt}$

\subsection{Daya Dukung}

Daya dukung tanah adalah kemampuan tanah dalam dalam menahan struktur pondasi bangunan, [15].

a. Daya Dukung Ijin Tanah Pondasi Tiang Tunggal

Perencanaan suatu struktur pondasi dengan baik, hendaknya memahami dasar-dasar daya dukung tanah [16]. Rumus yang digunakan untuk menghitung daya dukung tanah adalah metode Luciano Decourt (1982).

Luciano Decourt (1982): $Q u=(A p \times N p \times K)+A s \times\left(\frac{N s}{3}+1\right)$

dimana :

$\mathrm{Qu} \quad=$ Daya dukung ultimit tiang (ton)

Ap = luas penampang ujung tiang pondasi tiang (m2)

As $\quad=$ luas selimut $(\mathrm{m} 2)$

$\mathrm{K}=$ Koefisien tanah

$\mathrm{Np} \quad=$ rata - rata dari harga spt mulai $4 \mathrm{D}$ dibawah ujung tiang hingga $4 \mathrm{D}$ diatas tiang

Ns = factor keamanan nilainya antara $2,5 \mathrm{~s} / \mathrm{d} 3$, diambil Sebesar 2,5

$Q u=Q p+Q s$

Dimana :

$\mathrm{Qu} \quad=$ daya dukung tanah maksimum pada pondasi

Qp $\quad=$ resistance ultimit di dasar pondasi

Qs $\quad=$ resistance ultimit akibat lekatan lateral

$Q p=q p \times A p=(N p \times K) \times A p$

Dimana : 
$\mathrm{Np}=$ harga rata - rata SPT disekitar 4B diatashingga 4B dibawah Dasar tiang pondasi $(\mathrm{B}=$ diameter pondasi) $\sum_{1=i}^{n} \mathrm{Ni} / \mathrm{n}$

$\mathrm{K}=$ koefisien karakteristik tanah

$12 \mathrm{tm} / \mathrm{m} 2=117 \mathrm{kPa}$ untuk lempung

$20 \mathrm{tm} / \mathrm{m} 2=196 \mathrm{kPa}$ untuk lanau berlempung

$25 \mathrm{tm} / \mathrm{m} 2=245 \mathrm{kPa}$ untuk lanau berpasir

$40 \mathrm{tm} / \mathrm{m} 2=392 \mathrm{Kpa}$ untuk pasir

Ap = luas penampang dasar tiang

Qp = tegangan diujung tiang

$Q s=\beta\left(\frac{N s}{3}+1\right) \times A s$

Dimana :

Qs $\quad=$ Tegangan akibat lekatan lateral (ton)

$\beta \quad=$ Shaft coefficient

As $\quad=$ Keliling $\times$ Panjang tiang $(\mathrm{m} 2)$

Ns = harga rata - rata sepanjang tiang terbenam, [17].

b. Daya Dukung Ijin Tanah Pondasi Tiang Grup

Pondasi tiang grup merupakan pilihan apabila daya dukung ijin tanah pondasi tiang tunggal tidak mampu memikul beban struktur diatasnya, [18]. Daya dukung tiang grup yang digunakan pada tugas akhir ini berdasarkan keruntuhan tiang tunggal. Pada c-soils, c- $\varphi$ soils, dan $\varphi$ soils. Rumus yang digunakan untuk pondasi tiang grup adalah :

$Q u g=Q u$ t $\times n \times E F F$

Dimana :

Qug = Daya dukung ijin tiang group

Qut = Daya dukung ijin tiang tunggal

$\mathrm{n}=$ Jumlah tiang dalam grup

$\mathrm{EFF} \quad=$ Efisiensi tiang grup $(\leq 1)$

Untuk c-soils, $\mathrm{c}-\varphi$ soils $\rightarrow \mathrm{Eg}=0,7(\mathrm{~s}=3 \mathrm{~d})$ sampai $1(\mathrm{~s} \geq 8 \mathrm{~d})$

Untuk $\varphi$ soils $\rightarrow \mathrm{Eg}=1,[19]$.

\subsection{Kapasitas Daya Dukung Tanah}

Pondasi tiang pancang umumya dipasang secara berkelompok. maksud berkelompok adalah tiang yang dipasang secara berdekatan dengan jarak tertentu dan disatukan dengan menggunakan pile cap.

a. Kebutuhan Jumlah Tiang 
Dalam perencanaan pembuatan pondasi tiang pancang harus mengethahui jumlah tiang pancang yang dibutuhkan untuk memikul beban maksimum struktur diatasnya, jika pondasi tiang pancang tunggal kurang kuat untuk menahan beban maksimum diatasnya, maka bisa menggunakan pondasi tiangpancang grup. Rumus yang digunakan untuk menentukan kebutuhan jumlah tiang adalah :

$n=\frac{\text { Beban yang dipikul }}{\text { Daya dukung ijin tiang tunggal }}=\frac{P u}{Q u t}$ Atau $n=$ beban kolom : daya dukung ijin tiang tunggal

Dimana :

$\mathrm{n} \quad=$ jumlah tiang

$\mathrm{Pu} \quad=$ Beban kolom terbesar

Qut = Daya dukung ijin tiang tunggal, [20].

b. Jarak Tiang (s)

Jarak antar tiang pancang pada kelompok tiang pancang berpengaruh pada perhitungan kapasitas daya dukung.

Pada umumnya $S$ bervariasi antara : Jarak minimum $S=2 D$, dan Jarak minimum $S=6 D$

Berdasarkan fungsi pile misalnya : Sebagai friction pile minimum $S=3 d$ dan sebagai end bearing pile minimum $S=2,5 \mathrm{~d}$

Berdasarkan klasifikasi tanah : Apabila berada pada lapisan tanah liat keras minimum $\mathrm{S}=$ 3,5d dan apabila berada pada daerah lapis padat minimum $\mathrm{S}=2 \mathrm{~d}$

c. Efisiensi Tiang Group

Efisiensi sebuah tiang pancang grup adalah perbandingan kapasitas kelompok terhadap jumlah kapasitas masing-masing tiang pancang. Rumus untuk menghitung efisiensi kelompok tiang menggunakan rumus dari Conversi - Labar resebagai berikut :

$$
\begin{array}{ll}
E F F=1 & -\frac{\varphi}{90^{\circ}} \times \frac{(n-1) m+(m-1) n}{m \cdot n} \\
\text { EFF } & =\text { Efisiensi kelompok tiang } \\
\varphi & =\operatorname{arc~tg~} \mathrm{d} / \mathrm{s} \text {, dalam derajat } \\
\mathrm{m} & =\text { Jumlah baris tiang } \\
\mathrm{n} & =\text { Jumlah tiang dalam satu baris } \\
\mathrm{d} & =\text { Diameter tiang } \\
\mathrm{s} & =\text { Jarak pusat ke pusat tiang }
\end{array}
$$

\subsection{Perhitungan Pile Cap}

Pile cap ini bertujuan agar lokasi kolom benar-benar berada dititik pusat pondasi sehingga tidak menyebabkan beban tambahan pada pondasi. Pile cap hampir sama dengan kolom yang juga berfungsi untuk menahan gaya geser yang disebabkan pembebanan struktur diatasnya. Pile cap 
mempunyai bentuk yang bervariasi. Bentuk pile cap bisa berupa segitiga dan persegi panjang. Jumlah tiang pancang yang diikat pada setiap pile cap berbeda- beda. ada pile cap dengan pondasi tunggal, ada yang mengikat 2 dan 4 atau 6 buah pondasi yang diikat menjadi satu. Rumus - rumus dalam perencanaan pile cap sebagai berikut :

a. Perhitungan Beban Terfaktor

$\mathrm{Pu}=1,2 P_{D}+1,6 P_{L}$

Dimana :

$\mathrm{Pu} \quad=$ Beban Terfaktor 93

$\mathrm{P}_{\mathrm{D}} \quad=$ Beban Mati

$\mathrm{P}_{\mathrm{L}} \quad=$ Beban Hidup

b. Kontrol Gaya Geser Satu Arah

(1) Gaya geser yang bekerja pada penampang kritis :

$\mathrm{Vu}=2 \mathrm{x}$ Pumax $-\mathrm{W} 1-\mathrm{W} 2$

Dimana :

$\mathrm{Vu}=$ Beban Terfaktor $(\mathrm{Pu}) /$ Luas Penampang $(\mathrm{A})$

Pumax $=$ Panjang Pondasi

$\mathrm{W} 1=$ Berat beton

W2 = Berat tanah

(2) Kuat Geser Beton

$\varphi \mathrm{Vc}=\frac{1}{3} \times \sqrt{f c^{\prime}} \times \mathrm{b} \mathrm{x} \mathrm{d} \times 10^{-3}$

Dimana :

$\mathrm{b}=$ = lebar bidang geser

$\mathrm{d}=\quad=$ Tebal efektif pondasi

$\mathrm{fc}^{\prime}=$ Kuat tekan beton yang disyaratkan

Syarat $\varphi \mathrm{Vc}>\mathrm{Vu}$

c. Kontrol Gaya Geser Dua Arah

Gaya Geser yang bekerja pada penampang kritis :

$\mathrm{Fp}=\frac{1}{3} x \sqrt{f c^{\prime}}$

Dimana :

$\mathrm{Fp} \quad=$ tegangan geser

$\mathrm{Fc}^{\prime}=$ kuat tekan beton

Kuat Geser Beton

Menurut SNI-03-2847-2013 pasal 11, [21].

Nilai Vc haruslah yang terkecil dari beberapa rumus berikut 


$$
\Phi \times V n p=\Phi \times F p \times A p \times 103
$$

Syarat yang harus dipenuhi $\varphi \operatorname{Vnp}>$ Puk

\subsection{Tulangan atau Pembesian}

Pembesian pada konstruksi beton bertulang berfungsi sebagai penahan tegangan tarik. Mengenai rumus untuk menghitung volume besi beton bertulang sebagai berikut :

Atiang $=\mathrm{Fb}+\mathrm{n} . \mathrm{Fe}$

Ptiang $=\alpha b$. Atiang

Dimana :

Atiang = Luas tiang pancang tunggal

$\mathrm{Fb} \quad=$ Luas tiang pancang tunggal

$\mathrm{N}=$ Jumlah tiang pancang dalam 1 pile cap

$\mathrm{Fe}=$ = Luas tulangan dalam 1 tiang pancang, [22].

* Untuk panjang tulangan besi umumnya $12 \mathrm{~m}$

* Koefisien berat besi didapat $0,25 * 22 / 7 *(\varnothing \text { besi })^{\wedge} 2 * 785094$

* Cara mencari kebutuhan tulangan / besi :

Koef $\mathrm{x} \mathrm{p} \mathrm{x} \mathrm{j}=\ldots . \mathrm{kg}$

Dimana:

$\mathrm{K}=$ Koefisien berat besi

$\mathrm{P} \quad \quad=$ Panjang besi

$\mathrm{J}=$ Jumlah besi

\subsection{Stabilitas Kontrol}

Stabilitas kontrol adalah kontrol dimana stabilitas terhadap guling dan geser struktur bangunan.

- Kontrol Stabilitas terhadap Guling, dimana gaya yang memengaruhi akibat gaya Momen (Momen akibat gaya Vertikal dan Momen akibat gaya Horisontal ).

Disini tekanan tanah pasif $(\mathrm{Pp})$ dianggap $=\mathrm{O}\langle\mathrm{Pp}=\mathrm{O}\rangle$

Ambil $\Sigma$ M pada ujung tumit (toe) dinding $=\Sigma \mathrm{MR}$

Dimana Fs (cover turing) $=\frac{\text { momen yang akan menahan }}{\text { Momen yang akan meninggalkan }}$

Fs $($ over turing $)=\frac{\Sigma \mathrm{MR}}{\Sigma \mathrm{Mo}} \geq 1.5-2$

Dengan Faktor control : F > 1,5 (factor control keamanan), didapat dari Standart Nasional Indonesia (SNI), [23].

- Kontrol Stabilitas terhadap Geser, dimana gaya yang memengaruhi akibat gaya Vertikal dan gaya Horisontal( Lateral ). 
Fs (slidding $)=\frac{\sum \mathrm{v} \tan \left(k^{2}-\phi^{2}\right)+b \cdot k^{2} \cdot C^{2}+P p}{P a \cos \alpha} \geq 1.5$

Dimana :

$\mathrm{k}_{1}=\mathrm{k}_{2}=2 / 3$

$\mathrm{Pp}=1 / 2 \cdot \mathrm{Kp} \cdot \mathrm{J}_{2} \mathrm{D}^{2}+2 \cdot \mathrm{C}_{2} \cdot \mathrm{D} \cdot \sqrt{\mathrm{Kp}}$

- Kontrol terhadap daya dukung (bearing capacity)

Fs (bearing capacity) $=\frac{\mathrm{qv}}{\mathrm{Q} \max } \geq 3.0$

Dimana Q max/min $\frac{\Sigma V}{B}(1 \pm$ be / B $)$

$\mathrm{Qv}=\mathrm{c}_{2} \cdot \mathrm{Nc} \cdot \mathrm{Fcd} \cdot \mathrm{Fa}+\mathrm{q} \cdot \mathrm{Nq} \cdot \mathrm{Fqd} \cdot \mathrm{Fq}+1 / 2 \mathrm{y}_{2} \cdot \mathrm{Ny} \cdot \mathrm{Fyd} \cdot \mathrm{Fyl} \cdot \mathrm{B}^{1}$

- Rumus - rumus yang berkaitan dengan q diatas (qult dan qmax)

$\mathrm{e}=\mathrm{B} / 2 \cdot \frac{\Sigma \mathrm{MR}-\Sigma \mathrm{Mo}}{\Sigma \mathrm{V}}$

$q=y_{2} \cdot D$

$\mathrm{B}^{1}=\mathrm{B}-2 \mathrm{e}$

$\mathrm{Fcd}=1+0,4 \mathrm{D} / \mathrm{B}^{1}$

$\mathrm{Fqd}=1+2 \tan \emptyset_{2}\left(1-\sin \emptyset_{2}\right)^{2} \mathrm{D} / \mathrm{B}^{1}$

Fyd $=1$

Fei $=$ Fqi $=\left(1-\mathrm{w} / 90^{\circ}\right)^{2}:$ dimana $\mathrm{w}=\tan ^{-1} \frac{(\mathrm{Pa} \cos \alpha)}{\Sigma \mathrm{V}}$

- Ncy Ncp Ny merupakan faktor - faktor daya dukung yang tergantung pada besar $\varnothing_{2}$

- Harga Ncy Nqy Ny dapat diisi (dicari) menggunakan tabel.

Dengan factor control : F > 1,5 ( factor control keamanan ), didapat dari Standart Nasional Indonesia (SNI), [23].

- Kontrol stabilitas daya dukung, dimana gaya yang memengaruhi gaya vertical terhadap daya dukung tanah. Dengan factor control, Gaya Vertical < Daya Dukung Tanah

\subsection{Pengolahan Data}

Data yang sudah terkumpul akan diolah untuk mendapatkan hasil akhir guna penyusunan laporan tugas akhir ini. Data yang akan diolah sebagai berikut :

1. Gambar Rencana Struktur Atas

Gambar rencana struktur atas meupakan gambar digunakan untuk menghirung pembebanan pada strukturatas. Yang nantinya akan dipergunakan untuk perhitungan berikutnya.

2. Data Hasil Penyelidikan Tanah

Data hasil penyelidikan tanah ini akan digunakan sebagai perhitungan daya dukung tanah tiang pancang, hasil dari pengolahan tersebut berupa: Hasil tes SPT berupa tabel, daya dukung ijin tiang, kapasitas Daya Dukung Tiang : Kebutuhan Jumlah Tiang dan Jarak Tiang 
(s), perhitungan Pile Cap : Perhitungan Beban Terfaktor, Kontrol Gaya Geser Satu Arah, kontrol Gaya Geser Dua Arah, Perhitungan Tulangan Pile Cap.

\subsection{Data Teknis Tiang Pancang}

Dari SPT yang dilakukan di gedung Ketahanan Pangan Ngajuk ini, kita bisa mengetahui rencana dan ukuran pondasi tiang pancang yang akan digunakan.Untuk rencana gedung yang mau dibangun berukuran $67 \mathrm{~m}$ x $25 \mathrm{~m}$, berjumlah 4 lantai.

\subsection{Metode Analisa}

Dalam perhitungan perencanaan pondasi tiang pancang ini, penulis melakukan langkah - langkah sebagai berikut:

1. Menghitung kapasitas daya dukung tiang pancang antara lain : Data dari SPT dengan metode Luciano Decourt

\section{HASIL DAN PEMBAHASAN}

\subsection{Pembebanan}

Hasil pembebanan pada bangunan lantai 1 sampai 4 dengan Peraturan Pembebanan Indonesia peruntukan Gedung 1983, didapat :

a) Beban hidup + beban mati lantai $4=1536160,4 \mathrm{~kg}$

b) Beban hidup + beban mati lantai $3=1637804,4 \mathrm{~kg}$

c) Beban hidup + beban mati lantai $2=1536160,4 \mathrm{~kg}$

d) Beban hidup + beban mati lantai $1=1743464,4 \mathrm{~kg}$

* Total Pembebanan $(\mathrm{Wt})=6453589,6 \mathrm{~kg}=6453,6$ ton

* Beban Gempa= 0,77 detik

$*$ Beban Angin $=39,0625 \mathrm{~kg} / \mathrm{m} 2$

\subsection{Pondasi}

Dimensi serta kedalaman pondasi rencana yang digunakan sesuai perhitungan adalah :

1. Pondasi tipe 1 :

Panjang 3,6 $\mathrm{m}$ x lebar 3,6 $\mathrm{m}$ x tinggi 0,8 $\mathrm{m}$ dengan kedalaman $1 \mathrm{~m}$ dari muka tanah.

2. Pondasi tipe 2 :

Panjang 3,6 m x lebar 5,4 $\mathrm{m}$ x tinggi 0,8 $\mathrm{m}$ dengan kedalaman $1 \mathrm{~m}$ dari muka tanah

\subsection{Kebutuhan Tulangan}

a. Tulangan Pondasi Tiang Pancang tipe 1:

Menggunakan besi diameter $22 \mathrm{~mm}$, jarak $110 \mathrm{~mm}$, jumlah besi per pile cap 36 buah. Dengan total tulangan yang diperlukan 25747,4 kg.

b. Tulangan Pondasi tiang pancang tipe2 : 
Menggunakan besi diameter $22 \mathrm{~mm}$, jarak $60 \mathrm{~mm}$, jumlah besi per pile cap 60 buah. Dengan total tulangan yang diperlukan $44342.4 \mathrm{~kg}$.

c. Total kseluruhan kebutuhan tulangan adalah $70089.8 \mathrm{~kg}$.

\subsection{Stabilitas Kontrol}

Dikarenakan pondasi tpe 1 dan 2 hampir sama maka stabilitas hanya dihitung salah satu tipe saja.

a. Pondasi tipe 1 :

Kontrol terhadap kontruksi pondasi :

Kontrol terhadap guling 24,620 t/m2 >1,5 t/m2 $>$ Aman

Kontrol terhadap geser $9,156 \mathrm{t} / \mathrm{m} 2>1,5 \mathrm{t} / \mathrm{m} 2 ~->$ Aman

Kontrol penurunan kekuatan tumit :

Kontrol terhadap geser $-1,2779 \mathrm{t} / \mathrm{m} 2<15 \mathrm{t} / \mathrm{m} 2 \rightarrow$ Aman

Kontrol terhadap tarik $-0,7606 \mathrm{t} / \mathrm{m} 2<30 \mathrm{t} / \mathrm{m} 2->$ Aman

Kontrol kekuatan kaki :

Kontrol terhadap geser 1,3762t/m2<15 t/m2 -> Aman

Kontrol terhadap tarik 2,7676 t/m2<30 t/m2 -> Aman

Kontrol kekuatan badan :

б.max $1,910893 \mathrm{t} / \mathrm{m} 2<150 \mathrm{t} / \mathrm{m} 2->$ Aman

$\sigma . \min 2,769574 \mathrm{t} / \mathrm{m} 2<300 \mathrm{t} / \mathrm{m} 2->$ Aman

\section{KESIMPULAN}

Berdasarkan hasil perhitungan pondasi tiang pancang di Gedung Ketahanan Pangan Nganjuk didapat beberapa kesimpulan, yakni sebagai berikut :

1. Dari hasil analisis pembebanan yang terjadi pada Gedung Ketahanan Pangan Nganjuk bisa kita simpulkan bahwa :

Beban Hidup dan Beban Mati $=6453589 \mathrm{~kg}=6453,6$ ton

Beban Gempa $\quad=0,77$ detik

Beban Angin $\quad=39,0625 \mathrm{~kg} / \mathrm{m} 2$

2. Pondasi rencana yang digunakan sesuai perhitungan :

Pondasi tipe 1 : Panjang 3,6 $\mathrm{m}$ x lebar 3,6 $\mathrm{m}$ x tinggi 0,8 $\mathrm{m}$ dengan kedalaman $1 \mathrm{~m}$ dari muka tanah.

Pondasi tipe 2 : Panjang 3,6 $\mathrm{m}$ x lebar 5,4 $\mathrm{m}$ x tinggi 0,8 $\mathrm{m}$ dengan kedalaman $1 \mathrm{~m}$ dari muka tanah

3. Kebutuhan Tulangan :

Tulangan Pondasi Tiang Pancang tipe $1: 25747,4 \mathrm{~kg}$.

Tulangan Pondasi Tiang Pancang tipe $2: 44342,4 \mathrm{~kg}$.

Total kebutuhan tulangan : 70089,8 kg.

4. Perhitungan stabilitas kontrol semuanya aman 


\section{SARAN}

Beberapa saran daripenyusun yang perlu diperhatikan dalam perencanaan suatu kontruksi adalah sebagai berikut :

1. Perencanaan pondasi tidak hanya berpedoman pada ilmu tetapi berdasarkan pula pada pedoman yang biasa dilaksanakan di lapangan

2. Estimasi beban dan analisa statika harus tepat, guna mencapai target konstruksi yang aman dan memenuhi syarat seperti dalam perencanaan

3. Untuk mendapat hasil yang akurat, maka dibutuhkan pemahaman secara menyeluruh mengenai tahap - tahap dalam proses perencanaan, serta teori - teori yang didapat di bangku perkuliahan dan penerapan di lapangan

Penulis menyadari bahwa laporan tugas akhir ini masih jauh dari kata sempurna. Penulis mengharap akan kritik dan saran yang bersifat membangun guna penyempurnaan laporan tugas akhir ini. Demikian saran yang dapat disampaikan penyusun, semoga tugas akhir dari perencanaan pada gedung bertingkat dapat bermanfaat bagi kita semua.

\section{UCAPAN TERIMAKASIH}

Dalam penyusunan artikel ini, penulis ucapkan terimakasih kepada dosen pembimbing dan Universitas Kadiri. Penulis berharap agar artikel ini dapat bermanfaat bagi pembaca.

\section{DAFTAR PUSTAKA}

[1] H. C. Hardiyatmo, “Analisis dan Perancangan Fondasi.” 2010.

[2] A. I. Candra, A. Yusuf, and A. R. F, "Studi Analisis Daya Dukung Pondasi Tiang Pada Pembangunan Gedung Lp3M Universitas Kadiri,” J. CIVILA, vol. 3, no. 2, p. 166, 2018, doi: $10.30736 /$ cvl.v3i2.259.

[3] Joseph E. Bowles, “Analisa dan Desain Pondasi Jilid 1,” no. 9, pp. 1689-1699, 2013.

[4] F. Febriantoro, Y. C. S. P, and A. R. A, "STUDY PERENCANAAN PONDASI TIANG PANCANG JEMBATAN SEMBAYAT BARU II KECAMATAN MANYAR, KABUPATEN GRESIK,” Jurmateks, vol. 1, no. 1, pp. 148-159, 2018.

[5] H. A. E. Ismail and K. M. Gasmelseed, "Soil Consistency And Swell Potential Using Static Cone Penetration Machines," pp. 74-78, 1988.

[6] H. S. Sardjono, "Pomdasi Tiang Pancang Jilid 2,” Sinar Wijaya Surabaya, 1988.

[7] A. I. Candra, "ANALISIS DAYA DUKUNG PONDASI STROUS PILE PADA PEMBANGUNAN GEDUNG MINI HOSPITAL UNIVERSITAS KADIRI Agata," 
Ukarst, vol. 1, no. 1, pp. 63-70, 2017.

[8] D. Hartanto, Y. Cahyo, S. Winarto, and A. I. Candra, "PERENCANAAN PONDASI TIANG PANCANG PADA GEDUNG SEKRETARIAT DEWAN DPRD KABUPATEN KEDIRI,” Jurmateks, vol. 1, no. 2, pp. 303-312, 2018.

[9] S. Sosrodarsono and K. Nakazawa, Mekanika Tanah dan Teknik Pondasi. 2000.

[10] A. Kaprina, S. Winarto, and Y. C. SP, "ANALISA PRODUKTIFITAS ALAT BERAT PADA PROYEK PEMBANGUNAN GEDUNG FAKULTAS SYARIAH DAN ILMU HUKUM IAIN TULUNGANGUNG,” Jurmateks, vol. 1, no. 1, pp. 1-11, 2018.

[11] Badan Standarisasi Nasional, "RSNI T-02-200 Standar Pembebanan untuk Jembatan," 2005.

[12] Badan Standarisasi Nasional, "SNI 1725:2016 Pembebanan untuk Jembatan,” 2016.

[13] B. Direktorat Penyelidikan Masalah Bangunan, "Peraturan-Pembebanan-Indonesia1983." pp. 3-32, 1981.

[14] Badan Standarisasi Nasional, "SNI 1727:2013 Beban Minimum untuk Perancangan Bangunan Gedung dan Struktur Lain,” 2013.

[15] H. C. Hardiyatmo, Teknik Fondasi 1. 1996.

[16] L. Sintyawati, S. Winarto, A. Ridwan, and A. I. Candra, "STUDI PERENCANAAN STRUKTUR PONDASI TIANG PANCANG GEDUNG FAKULTAS SYARIAH IAIN PONOROGO,” Jurmateks, vol. 1, no. 2, pp. 227-237, 2018.

[17] H. Wahjudi, "Daya Dukung Pondasi Dalam.” 1999.

[18] Joseph E. Bowles, “Analisis dan Desain Pondasi Jilid 2,” 1986.

[19] J. Hadihardaja, "Rekayasa Pondasi II - Pondasi Dangkal dan Pondasi Dalam.” .

[20] E. Pamungkas, A., Harianti, "Desain Pondasi Tahan Gempa,” Desain Pondasi, 2013.

[21] Badan Standardisasi Nasional Indonesia, “SNI 2847 : 2013 Persyaratan Beton Struktural untuk Bangunan Gedung,” pp. 1-265, 2013.

[22] H. S. Sardjono, “Pondasi Tiang Pancang Jilid 1,” Sinar Wijaya Surabaya, 1988.

[23] B. Surendro, "Rekayasa Fondasi Teori dan Penyelesaian Soal,” Graha Ilmu, 2015. 